Portland State University

PDXScholar

1979

\title{
The effects of three stress modes on error productions of children with developmental apraxia of speech
}

Alan R. Horowitz

Portland State University

Follow this and additional works at: https://pdxscholar.library.pdx.edu/open_access_etds

Part of the Speech Pathology and Audiology Commons Let us know how access to this document benefits you.

Recommended Citation

Horowitz, Alan R., "The effects of three stress modes on error productions of children with developmental apraxia of speech" (1979). Dissertations and Theses. Paper 2760.

https://doi.org/10.15760/etd.2755

This Thesis is brought to you for free and open access. It has been accepted for inclusion in Dissertations and Theses by an authorized administrator of PDXScholar. Please contact us if we can make this document more accessible: pdxscholar@pdx.edu. 
AN ABSTRACT OF THE THESIS OF Alan Robert Horowitz for the Master of Science in Speech Communication: Emphasis in Speech Pathology/Audiology presented June 6, 1979.

Title: The Effects of Three Stress Modes on Error Productions of Children with Developmental Apraxia of Speech.

APPROVED BY MEMBERS OF THE THESIS COMMITTEE:

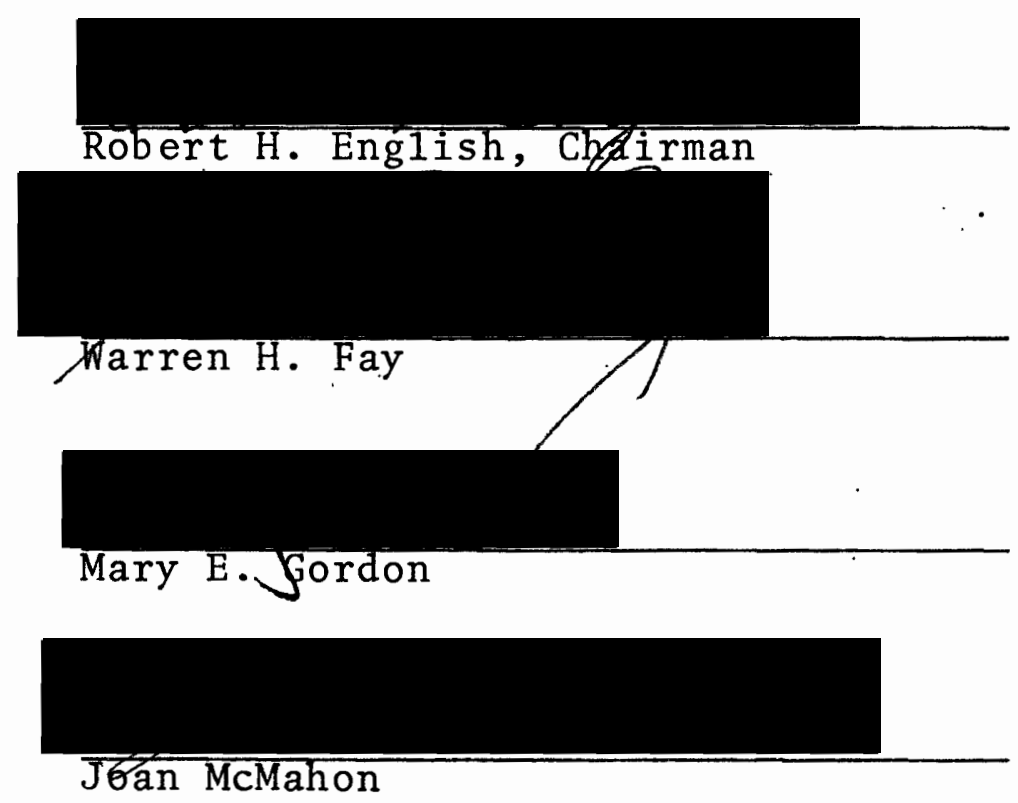

The use of facilitators to improve the articulation of children having developmental apraxia of speech (DAS) has been encouraged by Rosenbek et a1. (1974) and Yoss and Darley (1974). Among the facilitators mentioned are rhythmic body movement, modifications of intonation and stress, 
and visual cues, such as the written word. Rosenbek et al. (1974) strongly endorsed the use of stress, and especially equal and even stress.

In a discussion concerning adults, Rosenbek et al. (1973) described three stress modes they found to be effective. These modes were equal and even stress (EES), exaggeratedly normal stress (ENS), and approximately normal stress (ANS). For articulation training, the authors recommended a shaping procedure beginning with the most facilitative, EES, progressing to ENS, and ending with the least facilitative, ANS. Since it has been suggested that stress is an appropriate tool to use with children, it seems reasonable to extend the use of these three modes to children with DAS.

The purpose of this investigation was to study the effects of three modes of stress on error productions of children with developmental apraxia of speech during a sentence repetition task. The study was designed to answer the question:

Will there be a significant difference in the number of errors for each mode when: a) training to distinguish among the stress modes is not provided? b) training to distinguish among the stress modes is provided?

Secondarily, it was hypothesized EES would have the fewest errors, ENS would have significantly more errors than EES, and ANS would have the most errors when training is not provided and/or when training is provided.

A total of nine subjects with DAS were chosen from the 
Portland Public Schools and the Portland State University Speech and Hearing Clinic. The children had normal hearing in at least one ear, no concomitant disorder which might affect speech, and a mental age no more than three years below chronological age. The children were seen twice, with a period of at least one week between sessions. Each time they repeated 54 sentences composed of an Article-SubjectVerb-Article-Object presented in random order. Eighteen sentences were recorded using EES, eighteen using ENS, and eighteen using ANS.

The first presentation of stimuli, called Condition A, was preceded by the instruction to repeat the sentences exactly as heard. The second presentation of stimuli, called Condition $B$, was preceded by a training session in which the child demonstrated the ability to distinguish among the three stress modes. Responses under these two Conditions were analyzed for articulatory errors made on the subjects, verbs, and objects. Three comparisons were made with the results from each stimulus situation. The comparisons were: 1) between EES and ENS; 2) between EES and ANS; and 3) between ENS and ANS.

Results revealed a statistically significant difference for one of the six comparisons. EES had significantly fewer errors than ENS in Condition B. Neither EES nor ENS had significantly fewer errors than ANS. These findings do not support the assertion of Rosenbek and his colleagues (1973) 
that EES, followed by ENS, should precede the use of ANS in training. 
THE EFFECTS OF THREE STRESS MODES ON ERROR PRODUCTIONS OF CHILDREN-WITH DEVELOPMENTAL APRAXIA OF SPEECH

by

ALAN R. HOROWITZ

A thesis submitted in partial fulfillment of the requirements for the degree of

\author{
MASTER OF SCIENCE \\ in \\ SPEECH COMMUNICATION: \\ Emphasis in Speech Pathology/Audiology
}

Portland State University

1979 
TO THE OFFICE OF GRADUATE STUDIES AND RESEARCH:

The members of the committee approve the thesis of Alan Robert Horowitz presented June 6, 1979 .

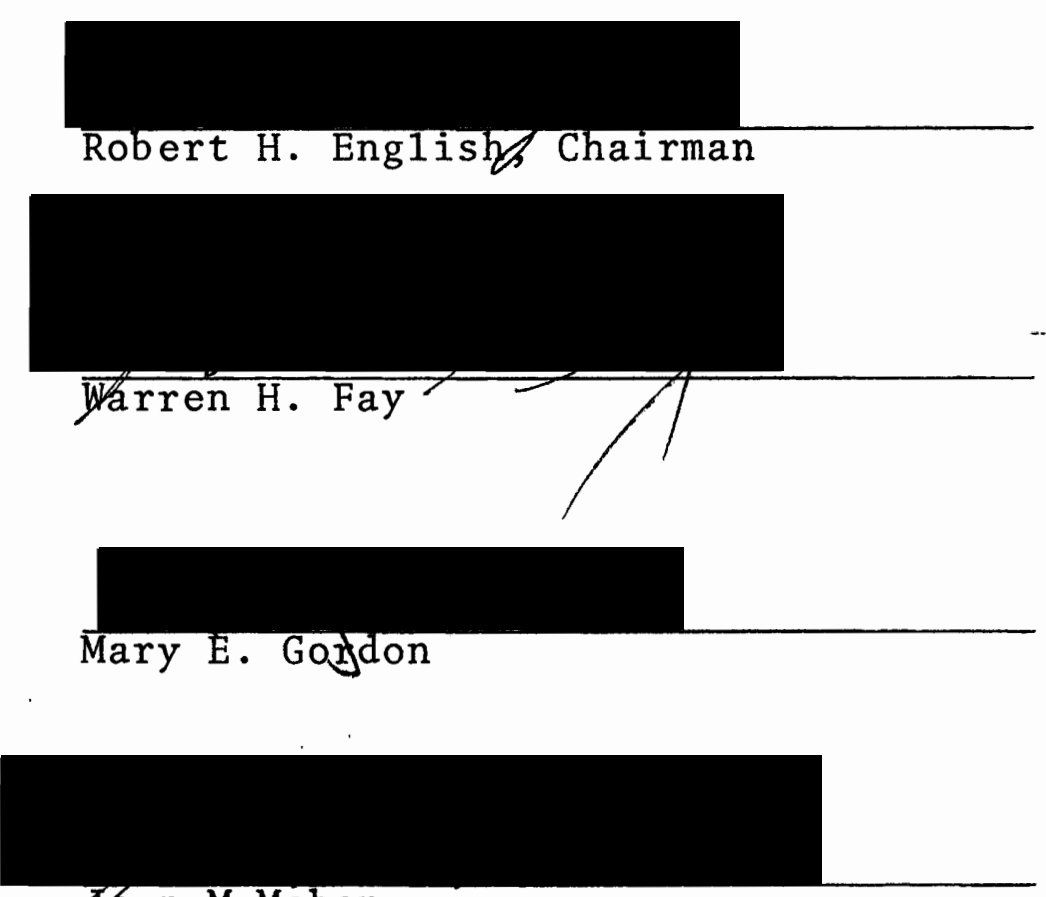

Jran McMahon

APPROVED :

Robert/W. Vogelsang, Head Department pf Speech Communication

Stanley E. Ratuch, Dean of Graduate Studies 


\section{ACKNOWLEDGMENTS}

I am deeply indebted to Warren H. Fay, Ph.D., of the University of Oregon Medical School, for assisting me in the design of this study and in the selection of subjects.

A special thank-you goes to the chairman of my thesis committee, Dr. Robert English, for generously sharing his knowledge of apraxia of speech and his skills in research methodology. His advice helped me succeed in this experiment and prepared me for undertaking future investigations.

Mary Gordon and my academic advisor, Joan McMahon, graciously provided me with moral support as well as practical suggestions. I extend my sincerest appreciation to these two individuals.

I offer my gratitude to Ted Grove, Ph.D., Department of Speech Communication, Portland State University, for directing statistical computations. Additional thanks are offered to Ronald Smith, Ph.D., Portland State's Department of Psychology, for his suggestions concerning statistical analysis.

For creating a warm environment at home that was conducive to study, I thank my wife, Judy. All the "little things" she did inspired me to pursue my task. 
TABLE OF CONTENTS

PAGE

ACKNOWLEDGMENTS . . . . . . . . . . . . . . . ii

LIST OF TABLES . . . . . . . . . . . . . . . . vi

CHAPTER

I INTRODUCTION AND STATEMENT OF PURPOSE . . 1

Introduction. . . . . . . . . . 1

Statement of Purpose. . . . . . 2

Definitions . . . . . . . . 3

II REVIEW OF THE LITERATURE. . . . . . . . 5

Incidence and Etiology of DAS . . . 5

Characteristics of DAS. . . . . . 6

Nature of the Disorder. . . . . . 8

Apraxia of Speech as a

Motor Programming Disorder. . . . 9

Apraxia of Speech as a

Sensory-Motor Disorder. . . . 10

Apraxia of Speech as a

Language Dependent Disorder . .

Training the Client with DAS. . . . 15

II METHODS AND PROCEDURES. . . . . . . . . . 19

Genera1 P1an. . . . . . . . . 19

Subjects............. . . 19

Instrumentation . . . . . . . 20 
CHAPTER

Test Stimuli . . . . . . . . 21

Test Setting.......... . . 22

Testing Procedures......... 22

IV RESULTS AND DISCUSSION . . . . . . . 24

Results............ . 24

Discussion ........... . . . 27

$\mathrm{V}$ SUMMARY AND IMPLICATIONS . . . . . . . 32

Summary. . . . . . . . . . 32

Implications . . . . . . . . . 34

Research .......... . 34

Clinical . . . . . . . . 35

BIBLIOGRAPHY . . . . . . . . . . . . . 37

APPENDICES

A SPECIFICATIONS OF ELECTRONIC EQUIPMENT USED IN THIS STUDY . . . . . . . . . . 41

B LIST OF STIMULI. . . . . . . . . . . 43

C TRAINING PROCEDURE FOR CONDITION B . . . 45

D SEX, CHRONOLOGICAL AGE, MENTAL AGE, AND SCORES OF SUBJECTS . . . . . . . . . . . 


\section{LIST OF TABLES}

TABLE

PAGE

I Mean Scores and Standard Deviations for Conditions A and B. . . . . . . . 25

II Comparisons of Stress Modes Using t-Values . 
CHAPTER I

INTRODUCTION AND STATEMENT OF PURPOSE

\section{Introduction}

According to Morley and Fox (1969), developmental apraxia of speech (DAS) is:

- . the failure or limited ability to control and direct the movements and coordinations of the respiratory, laryngeal, and oral muscles for articulation when muscle tone and movement is otherwise adequate, and as differentiated from dysarthria.

Treatment of this disorder has not been successful in the past. Lengthy treatment has usually resulted in slight improvement (Yoss and Darley, 1974). Recently, 1iterature dealing with treatment of DAS has encouraged the use of prosody to facilitate articulation. In a correspondence with this investigator, Rosenbek (1978) stated possibly the clinician can manipulate sound production by altering the three suprasegmentals, pitch, stress, and pause time. He was particularly optimistic about the effects of stress on sound production.

In a paper delivered at the Third Conference on Clinical Aphasiology in Albuquerque, 1973, Rosenbek et a1. proposed the use of three modes of stress in treatment of apraxia of speech in adults. Although this article was 
directed toward adult clients, Rosenbek et al. (1974) have stated that modification of stress is also useful with children. This assertion was supported by Yoss and Darley (1974). The three stress modes were equal and even stress, exaggeratedly normal stress, and approximately normal stress. When training reaches the phrase or sentence stage, the clinician presents a stimulus using equal and even stress and the client repeats it. Then they begin to approximate normal speech while maintaining correct articulation of the target sound.

\section{Statement of Purpose}

The purpose of this investigation was to study the effects of three stress modes on error productions of children with developmental apraxia of speech during a sentence repetition task. The three modes of stress were equal and even stress, exaggeratedly normal stress, and approximately normal stress. The study was designed to answer the question:

Will there be a significant difference in the number of errors for each mode when: a) training to distinguish among the stress modes is not provided (i.e. Condition A)? b) training to distinguish among the stress modes is provided (i.e. Condition $B$ )?

Secondarily, it was hypothesized equal and even stress would have the fewest errors, exaggeratedly normal stress would have significantly more errors than equal and even 
stress, and approximately normal stress would have the most errors when training is not provided and/or when training is provided.

\section{Definitions}

The following terms were operationally defined for the purposes of this investigation.

\section{Developmental Apraxia of Speech}

Developmental apraxia of speech (DAS) is defined as a condition in which: 1) volitional control of articulation is impaired; 2) there is no sign of weakness, slowness, or incoordination of speech musculature; and 3 ) onset occurred prior to development of normal articulation.

\section{Stress}

Stress is defined by Rosenbek (1976) as the relative prominence of speech syllables compared with that of companion syllables. Generally speaking, pitch, loudness, articulation time (duration), and pause time are altered when stressing a syllable during speech production.

For purposes of this study, three stress modes were used. First, equal and even stress (EES) was characterized by approximately equal increase in intensity and duration of each monosyliabic word in the sentence. In addition, each stressed word was preceded by a pause. Second, exaggeratedly normal stress (ENS) preserved normal stress contours 
while emphasizing overall rate reduction. Duration and loudness of the stressed syllable was simultaneously increased. The pitch was slightly higher on the stressed element than on the adjacent syllables. As in EES, stress was further emphasized by a momentary pause prior to phonation. Finally, approximately normal stress (ANS) was described by the same features as ENS, but to a less marked degree.

The stimuli were presented to three speech pathology graduate students, who decided in which mode each sentence fe11. Two out of the three students judged the production to be in the appropriate mode in order for it to be included in the study. 


\section{CHAPTER II}

\section{REVIEW OF THE LITERATURE}

DAS has been diagnosed in this country only since 1968 (Ferry, Hall, and Hicks, 1974). Recently, it has received increasingly more attention from researchers. Although a majority of the literature dealing with apraxia of speech is concerned with adults, the following discussion will focus mainly on children having DAS. Only in the sections dealing with the nature of the disorder and its treatment will adult literature be presented, since such information may be useful in understanding DAS in children.

\section{Incidence and Etiology of DAS}

According to Ferry, Ha11, and Hicks (1974), probably 10 percent of the school-age articulation problems are the result of DAS. The ratio of males to females with the disorder is three to one. DAS is first seen in children between the ages of $2 \frac{1}{2}$ and 9 years, and is found often where a positive family history of speech impairment exists.

Although it is known DAS results from brain damage, the exact nature of the damage is not known. It appears neural damage is diffuse within the brain. Edwards (1973) 
and Ferry, Ha11, and Hicks (1974) have stated DAS may be due to impairment of neural and muscular function, rather than to anomalies of specific anatomical structures. Edwards (1973) considered the functiona1 impairment to be in the sensory and motor pathways for speech, or in pathways linking these neurological processes.

Ferry, Hal1, and Hicks (1974) hypothesized DAS may be the result of brain damage incurred before birth. According to these authors, the very intricate neural connections linking the articulators to the brain may be disturbed during development, producing the clinical picture seen in children with DAS.

Finally, Morley and Fox (1969) pointed to possible genetic influences for DAS which, incidentally, also are responsible for cleft palate. These include maternal infection, maternal dietary imbalance, maternal hormone activity, toxicity and medication.

\section{Characteristics of DAS}

The main difficulty evidenced by children with DAS is the volitional control of sound sequences (Chappe11, 1973; Rosenbek et a1., 1974). Usually, the longer the sequence, the more difficult it is to produce. According to Chappel1 (1973), children with this disorder exhibit poor ability to imitate words, phrases, and sentences. Edwards (1973), on the other hand, stated imitation of single words and short 
automatic phrases may be reasonable. Both authors agreed stretches of spontaneous creative speech may reveal faulty articulation.

Another characteristic is the inconsistency of errors (Morley and Fox, 1969; Fawcus, 1971; Edwards, 1973; Ferry, Ha11, and Hicks, 1974; Rosenbek et a1., 1974). This feature has been described by Morley and Fox (1969) as the ". . erratic use of phonetic sounds as they occur in varying phonemic sequences." For instance, Edwards (1973) gives the example of alveolar sounds being substituted by velar sounds, while there may be erratic realization of manner of production.

Children with DAS have difficulty producing phonemes which require complex articulatory adjustments, e.g., fricatives, affricates, and consonant clusters (Rosenbek and Wertz, 1972; Chappe11, 1973; Edwards, 1973). Misarticulations sometimes include vowels as well (Rosenbek and Wertz, 1972).

A characteristic which has diagnostic significance is the presence of groping trial-and-error behavior (Rosenbek and Wertz, 1972). This difficulty manifests itself as sound prolongations, repetitions, and silent posturing preceding or within imitative utterances.

Related to the groping behavior are disturbances in prosody. It may be disturbed because the child tries to compensate for difficulty articulating sounds (Rosenbek 
and Wertz, 1972; Edwards, 1973; Rosenbek et a1., 1974; Yoss and Darley, 1974). Disturbed prosody is observed most often in imitative speech and is characterized by slow rate, even stress, and inappropriate pauses. Prosody may be normal if the child is not pressured to be intelligible.

Finally, a common characteristic is delayed speech development (Rosenbek and Wertz, 1972). Language reception is usually much better than expression. Nevertheless, language reception may be negatively influenced by coexisting language deficits and learning disability.

\section{Nature of the Disorder}

There are at least three popular interpretations of the disorder. First, it has been seen as a motor programming disorder. Blakeley (1972) stated DAS is the breakdown of muscle function associated with talking. Furthermore, he noted ". . . dyspraxia is a breakdown in articulation related to positional and movement sense."

Secondly, DAS has been viewed as a sensori-motor disorder. Edwards (1973) said proprioceptive input may be impaired, resulting in failure to program, organize, and execute articulatory movements. In addition, she noted impairment of the auditory and tactile systems possibly are responsible for deficient monitoring of speech. Fawcus (1971) wrote that these children may have difficulty organizing input from several modalities. 
A third view of DAS can be inferred from Martin's (1974) discussion of apraxia of speech in adults. He stated it is a language dependent disorder in which the individual does not obey the phonological rules of the language. According to Martin, the phonological rule system is part of the language system and sequencing of phonemes is a linguistic act.

Each of these views has been studied using adults as subjects. Since information found with adults may increase knowledge of children with DAS, some studies of adults having apraxia of speech will now be presented. The reader, however, should use caution when applying information from. these studies to children.

Apraxia of Speech as a Motor Programming Disorder

A study by DiSimoni and Darley (1977) was undertaken to find the programmatic relationship between increased utterance length and phoneme duration in apraxia of speech. The authors asked a 23-year-old female with apraxia resulting from head injuries to repeat three test utterances: "/ipi/; /ipi/ saw /ipi/; /ipi/ saw /ipi/with /ipi/." Durations of the $/ \mathrm{p} /$ in the first syllable were compared to equivalent data for subjects with normal speech.

The subject with apraxia of speech performed differently from subjects with normal speech. First, while duration of the /p/ decreased as utterance length increased for 
subjects with normal speech, the duration of the $/ \mathrm{p} /$ increased with longer utterances for the subject with apraxia. The authors concluded apraxia led to inefficient articulatory programming of longer utterances. This interpretation is supported in the literature by descriptions which state that articulation deteriorates with increased utterance length (Rosenbek and Wertz, 1972; Chappe11, 1973). Second, findings showed the $/ \mathrm{p} /$ phonemes produced by the subject with apraxia were completed more rapidly than those produced by subjects with normal speech for the one- and three-word conditions. On the other hand, production of the /p/ was slower than normal for the five-word condition. This result was interpreted to mean the articulatory system of the subject with apraxia was responding to false information that overestimated the length of the input to be programmed. As a result, the system could respond no faster when the fiveword condition was reached and the feed-forward was disturbed. Findings from this study suggest management of apraxia of speech should focus on smaller units.

Apraxia of Speech as a Sensory-Motor Disorder

Because apraxia of speech has traditionally been viewed as a motor disturbance, little research has been conducted relative to the possible existence of sensory-motor impairment. Among studies in this area are the somewhat contradictory investigations by Atens, Johns, and Darley (1971), 
and Rosenbek, Wertz, and Darley (1973) .

Atens, Johns, and Darley (1971) studied auditory perception of sequenced words in adults with apraxia of speech. The experimental group consisted of three females and seven males; the control group contained 10 adults with no speech impairments. Subjects were instructed to point to pictures designated by auditory stimuli. The stimuli consisted of 190 sequences of either two or three words, with minimal variation of initial consonant, final consonant, medial vowel or multiple phonemes.

Although the group with apraxia of speech was heterogeneous, they tended to have significantly lower scores than normal subjects. Three subjects scored within the normal range of 98-99 percent, three scored between 93 and 94 percent, but the four lowest scored between 76 and 89 percent. The investigators concluded there was no support for the hypothesis that the articulatory disturbances characteristic of apraxia of speech are related to auditory perceptual difficulty. They supported this conclusion by stating some subjects with apraxia of speech have little or no difficulty in perceiving sequences of phonemically varied words. Nevertheless, they noted the articulation of some subjects having the disorder may be complicated by reduced auditory memory for phonemically varied sequences of words.

In another study, Rosenbek, Wertz, and Darley (1973) investigated oral sensation and perception in 30 adults 
with apraxia of speech, 10 adults with aphasia and no apraxia of speech, and 30 adults with no speech impairment. Three oral sensory-perceptual measurements were used: oral form identification, two-point discrimination, and mandibu1ar kinesthesia.

Results showed subjects with apraxia of speech have more difficulty processing orally received sensory information than normal or aphasic subjects. The severity of apraxia of speech correlated positively with severity of sensory-perceptual deficit. While certain subjects with mild apraxia of speech did not exhibit oral sensory-perceptual deficits, subjects having a more severe form of the disorder demonstrated such deficits.

The results from these two studies do not clearly point to apraxia of speech as a sensory-motor disturbance. At this time, it can be said only that in certain cases adults with this disorder may have sensory-perceptual disturbances as part of the overall problem of articulation disorder.

Apraxia of Speech as a Language Dependent Disorder

Recently, Martin (1974) proposed that apraxia of speech is not a disorder specific to sensory or motor pathways. He said it is a linguistic impairment affecting selection and combination of phonemes according to rules of the language. As such, he noted it is basically no 
different than selection of words for an utterance and combination of words according to syntactic rules.

Researchers have studied the effects of linguistic variables on errors. Deal and Darley (1972) undertook such a study using adults with apraxia of speech as subjects. Using Brown's (1945) method, they weighted words according to grammatical class, difficulty of initial phoneme, sentence position, and word length. Subjects were asked to read a short selection of about 100 words.

Findings indicated errors increased along with word weight. The combination of grammatical class and word length had the most significant effect. Errors increased on nouns, adjectives, verbs, and adverbs more than five letters in length. The authors inferred that since these grammatical classes carry linguistic weight, by reason of their high information value, their production places stress on the speech system. In addition, it was noted that since apraxia of speech is a disorder of proper sequencing, it is logical that longer words would be affected most.

Dunlop and Marquardt (1977) investigated the effects of grammatical class, phoneme position, and phoneme difficulty on errors of 10 adults with apraxia of speech. The three grammatical classes studied were nouns, verbs, and adjectives. The authors also attempted to determine the relationship between word abstraction and errors on monosyllabic words. Subjects repeated sentences containing the 
words under investigation.

Un1ike the findings of Deal and Darley (1972), the study by Dunlop and Marquardt showed grammatical class did not have a significant effect on errors. Nevertheless, abstraction level did positively correlate with error productions, thus signaling a linguistic effect on phonemic production. Other results demonstrated errors were affected by phoneme difficulty, but not phoneme position. Dunlop and Marquardt maintained differences between the studies in stimuli and procedures may have accounted for different findings concerning grammatical class. Whereas these researchers used words five phonemes or less in length repeated from an auditory model, Deal and Darley included words having more than five phonemes read from the printed page. It appears, while the use of shorter words may make the task easier, the lack of visual feedback from auditory stimuli may cause it to be more difficult.

Hardison, Marquardt, and Peterson (1977) investigated the effects of abstraction level, active and passive voice, and noun phrase position on errors of 10 adults with apraxia of speech. Stimuli were sixty consonant-vowel-consonant monosyllables placed in sentences. Twenty of the monosyllables were concrete nouns, 20 were abstract nouns, and 20 were nonsense nouns. Each sentence was presented by the experimenter in its entirety and again with the stimulus word missing. The subject then produced the omitted word. 
A11 three variables significantly influenced errors. First, subjects made more errors when the stimulus word was at the beginning of the sentence. Second, sentences using the passive construction were more difficult. Finally, more errors occurred on nonsense and abstract nouns than on concrete nouns. Hardison and her colleagues concluded apraxia of speech is influenced by semantic and syntactic factors.

In each of the studies cited, a linguistic factor has been shown to influence articulation of adults with apraxia of speech. The evidence points to speech motor programming as related to other facets of the language system.

\section{Training the Client with DAS}

Returning to the literature concerned with children, the principle upon which training should be based is to ". . help the child acquire as near normal volitional speech as physiological limitations will allow" (Rosenbek et al., 1974). Since the child's response adequacy may be limited because of brain damage, the clinician must develop goals accordingly. Instead of setting a goal of normal speech, the clinician should strive for improved speech and communication ability.

Training should use facilitative techniques. According to Rosenbek (1976), facilitation is the process whereby conditions are established so a patient's access to his 
phonological system is improved. The implication is that the patient knows the complete speech sound repetoire, but certain conditions prevent access to it. Although facilitation involves shaping the client's response, it also emphasizes ". . simple manipulation of the stimulus (rhythm, rate, loudness, etc.)" (Rosenbek, 1976).

Modification of the prosody of a stimulus phrase or sentence by the clinician is facilitative (Edwards, 1973; Rosenbek et a1., 1974; Yoss and Darley, 1974). This approach is based on the theory that rhythm serves as a timing device for articulation (Lennenberg, 1967). Prosody of speech is made from features called suprasegmenta1s. That is to say, the form of the sentence can be varied by altering its pitch or intonation contour, by changing stress from one word to the next, or by changing pauses between sentence segments (Bloom and Lahey, 1978).

Yoss and Darley (1974) observed that drills requiring echoing of phrases and sentences led to fewer errors when stress and intonation patterns were altered by the clinician. Instead of using a steady, even tone such as "Please... pass...the...salt," the clinician added stress by saying "Please pass the salt" or "Please pass the sa1t" or "Please pass the salt." This example resembles exaggeratedly normal stress (ENS) described by Rosenbek et a1. (1973) and mentioned in Chapter I.

A technique that works we11 with modification of 
prosody is the use of rhythmic body movement (Edwards, 1973; Rosenbek et al., 1974; Yoss and Darley, 1974). For example, the client speaks a word or phrase while beating time with an arm or squeezing a bean bag during production of each syllable. This pairing of a gestural movement with a speech act is a form of what Luria called intersystemic reorganization (Rosenbek, 1976). This term represents the introduction into the performance of an act a functional system that was not previously a part of that performance.

Another approach utilizing intersystemic reorganization is Melodic Intonation Therapy (MIT) (Sparks and Holland, 1976). This involves a process whereby clients keep time with their arms while melodically producing utterances. As they gradually learn to approximate normal intonation, they phase out arm movement. MIT is directed toward adults with expressive language impairment, but clinicians have successfully adapted it to improve slurred speech and to help reduce the frequency of phonemic errors in some adults with aphasia (Sparks and Holland, 1976). Perhaps this technique can be further developed to help children with DAS.

The work of Tonkovich and Marquardt (1977), although relating to adults, is appropriate to consider here since findings may have implications for treatment of children. They investigated the effects of MIT and normal stress on articulation of 10 adults with apraxia of speech. Sentence stimuli were presented to the subjects via videotape record- 
ings utilizing melodic intonation and normal prosody. In addition, stress was selectively employed over words in the beginning, middle, and end of the sentences. Subjects did 1ess well when melodic intonation was the mode of presentation. The authors attributed this to the increased volitional effort necessary for intoning responses without previous practice. Subjects, however, made fewer errors on words which received primary stress in the stimulus sentence. 
CHAPTER II I

METHODS AND PROCEDURES

\section{General Plan}

Sentence stimuli recorded on audio tape cards were randomly presented to each subject on two separate occasions using a Language Master. During the first presentation, Condition $A$, subjects were instructed to repeat the sentences exactly as they heard them. During the second presentation, Condition $B$, repetition of the stimuli was preceded by listening training in which the subject demonstrated his ability to distinguish among the three stress modes used in this experiment. Condition B followed Condition A by at least one week.

\section{$\underline{\text { Subjects }}$}

Subjects consisted of nine children ranging in age from 7 years, 11 months, to 10 years, 1 month. Al1 subjects had been diagnosed by speech pathologists as having DAS. For data to be obtained from this experiment, subjects needed to demonstrate articulation errors when repeating the stimuli. Therefore, only children with a relatively severe form of DAS were used. Because many subjects had been diagnosed 
more than a year before, severity was judged by a combination of teacher opinion and examiner observation when conversing with the child.

Eight subjects were selected from the Portland Public Schools and one was selected from the Speech and Hearing files at Portland State University. Subjects exhibited the following characteristics:

1. A receptive language delay of no more than three years, according to the Peabody Picture Vocabulary Test, Form A.

2. Hearing within normal limits based on a pure-tone audiometric screening at an intensity 1 eve1 of 25 $\mathrm{dB}$ for the frequencies 500, 1000, 2000, and 4000 $\mathrm{CPS}(\mathrm{Hz})$ unilatera11y.

3. No concomitant abnormality which might be of etiologic significance to the speech disorder. For instance, subjects with dysarthria, aphasia, and autism were excluded.

\section{Instrumentation}

Special electronic equipment used included the Language Master, an Ar-Tik Speech and Hearing Recorder, and a Beltone Portable Audiometer. In addition to electronic equipment, the Peabody Picture Vocabulary Test, Form A, was administered. These instruments are described below with specifications for electronic equipment provided in Appendix A.

1. Language Master. An electronic device for recording and playing back sounds. It utilizes 9 inch $X$ 3 inch cards with a $\frac{1}{4}$ inch strip of magnetic tape specially bonded $\frac{1}{2}$ inch above the bottom margin. A card is placed in a slot and is automatically fed past either a record or playback head, depending on the setting of the switch. Four seconds of material may be recorded on each card. 
2. Ar-Tik Speech and Hearing Recorder. A specially designed high-fidelity ree1-to-ree 1 recorder that operates at a speed of $7 \frac{1}{2}$ ips. Although any tape can be used, it is recommended by the manufacturer that $1.0 \mathrm{mil} 1800^{\prime}$ tape be used (Arion Products). Playback is monitored with the use of headphones.

3. Beltone Portable Audiometer, Mode1 10-D. A wide range audiometer that utilizes the frequency range 125-8000 CPS. It was calibrated monthly according to ANSI-1969. It utilized TDH-39 earphones.

4. Peabody Picture Vocabulary Test, Form A. A test designed to provide an estimate of a subject's verbal intelligence through measurement of hearing vocabulary. The test includes a spiral-bound book containing 150 plates preceded by three example plates, an examiner's manual, and individual test records for scoring responses. Each plate contains four pictures. The examiner says a word representing one of the pictures and the subject indicates, with a verbal response or by pointing, which picture he chooses. The test is discontinued when a basal and ceiling have been established.

\section{Test Stimu1i}

Stimuli were six active declarative sentences composed of an Article-Subject-Verb-Article-Object. The subjects, verbs, and objects were familiar consonant-vowel-consonant (CVC) monosyllabic words. A list of test stimuli appears in Appendix B. The sentences were recorded on audio-tape cards as they were produced by an adult female having no speech or language disorders. Each sentence was recorded nine times: three times with equal and even stress (EES), three times with exaggeratedly normal stress (ENS), and three times with approximately normal stress (ANS). In ENS and ANS, each sentence was recorded once with primary stress on the subject, once on the verb, and once on the object. 


\section{Test Setting}

A11 testing was conducted individually and distractions were minimal during the examination. Testing for the subjects in Portland Public Schools was done at the subject's school. The subject from the Portland State University Speech and Hearing Clinic was tested in a clinic room.

\section{Testing Procedures}

Testing was divided into Conditions $A$ and $B$. The hearing screening was administered at the beginning of Condition A. Following that, the Peabody Picture Vocabulary Test, Form A, was administered, except to children who had already taken it during the 1978-79 school year. The examiner then presented a choice of toys to each subject with instructions to select one. This toy was given to the child as a reward following the session. The examiner stressed that good 1 istening and hard work were necessary to earn the prize.

The subject was then instructed to listen to each sentence and repeat it. Three sample stimulus cards were presented to condition the subject to respond appropriately. When the subject had successfully repeated the sample utterances, 30 of the 54 sentences were presented, followed by a short break and presentation of the remaining 24 sentences. 
In Condition B, which followed Condition A by at least one week, the subject was presented again with some toys and instructed to choose one. The toy was given to the child at the end of the session, as in Condition A. Next, the subject was trained to distinguish among the three stress modes. The training procedure can be found in Appendix C. Following training, the stimuli were presented as in Condition A.

The stimulus cards were numbered and the examiner marked the order of presentation for each subject prior to the beginning of each session. Stimuli were presented using the same random order for each subject in Conditions $A$ and $B$. Responses were recorded using the Ar-Tik recorder and were scored once at the time of the utterance and later from the recorded sample as a check for accuracy. 


\section{CHAPTER IV \\ RESULTS AND DISCUSSION}

\section{$\underline{\text { Results }}$}

The purpose of this experiment was to investigate the effects of three stress modes on error productions of children with DAS during a sentence repetition task. There were 54 sentences presented on two separate occasions to each child. The first time, called Condition A, training to distinguish among the stress modes was not provided. The second time, called Condition $B$, training to distinguish among the stress modes was provided.

The study was designed to answer the following question:

Will there be a significant difference in the number of errors for each mode when: a) training to distinguish among the stress modes is not provided? b) training to distinguish among the stress modes is provided?

Secondarily, it was hypothesized EES would have the fewest errors, ENS would have significantly more errors than EES, and ANS would have the most errors when training was not provided and/or when training was provided.

Raw data, sex, chronological ages, and mental ages for each subject can be found in Appendix D. For purposes of 
this investigation, 1inguistic errors were separated from phonemic errors. Since visual inspection revealed linguistic errors did not affect the statistical outcome, they were disregarded when scoring.

Mean number of errors and standard deviations for each mode are shown in Table I. A possible 54 errors existed for each subject in each stress mode. In Condition $A$, the mean scores for the modes were $21.88,21.44$, and 22.11 respectfully. Standard deviations were 15.26, 15.14, and 15.83 . In Condition $B$, the mean scores for the modes were 20.44, 22.11 , and 21.55 respectfully. Standard deviations were $15.94,16.22$, and 15.43 . The large standard deviations probably reflect the wide variation in severity of DAS among subjects.

TABLE I

MEAN SCORES AND STANDARD DEVIATIONS FOR CONDITIONS A AND B

\begin{tabular}{|c|c|c|c|}
\hline \multicolumn{2}{|c|}{ MODES } & CONDITION A & CONDITION B \\
\hline EES & $\overline{\mathrm{X}}$ & 21.88 & 20.44 \\
\hline & Sd & 15.26 & 15.94 \\
\hline ENS & $\bar{X}$ & 21.44 & 22.11 \\
\hline & $\mathrm{Sd}$ & 15.14 & 16.22 \\
\hline ANS & $\overline{\mathrm{X}}$ & 22.11 & 21.55 \\
\hline & $\mathrm{Sd}$ & 15.83 & 15.43 \\
\hline
\end{tabular}


To further analyze the obtained data, a $t$-test for correlated means was used. Three comparisons were made for each of the two Conditions. The comparisons were: 1) between EES and ENS; 2) between EES and ANS; 3) between ENS and ANS. Table II contains $t$-scores for each of the three modes in both Conditions. of the six comparisons, it can be seen only one resulted in a significant difference at the .05 level of confidence. This was the comparison between EES and ENS in Condition B. To test the finding that the difference between EES and ENS was significant, a Rho correlation was obtained. The result 1.0 indicates the difference is statistically significant.

TABLE II

COMPARISONS OF STRESS MODES

US ING $t$-VALUES

\begin{tabular}{l|cc|cc}
\hline \multirow{2}{*}{ MODES } & \multicolumn{2}{|c|}{ CONDITION A } & \multicolumn{2}{c}{ CONDITION B } \\
& $t$-value & Significance & $t$-value & Significance \\
\hline $\begin{array}{l}\text { EES and } \\
\text { ENS }\end{array}$ & 1.17 & N.S. & 3.01 & $\mathrm{~S}$. \\
$\begin{array}{l}\text { EES and } \\
\text { ANS }\end{array}$ & .30 & N.S. & 1.64 & N.S. \\
$\begin{array}{l}\text { ENS and } \\
\text { ANS }\end{array}$ & 1.03 & N.S. & .54 & N.S. \\
\hline
\end{tabular}

$$
\mathrm{d} f=8
$$

N.S. = Not significant at the .05 level of confidence

S. = Significant at the .05 level of confidence 


\section{Discussion}

Data from this investigation reveal the answer to part a) of the question is, there is no significant difference in the mean number of errors for each of the three modes when training is not provided. The answer to part b) is, there is a significant difference between EES and ENS, but not between EES and ANS or between ENS and ANS when training is provided. The finding that EES had significantly fewer errors than ENS in Condition B confirms part of the hypothesis. However, since neither EES nor ENS had significantly fewer errors than ANS, the hypothesis is not completely supported.

In order to better understand the results from this study, two questions for discussion will be considered. The first is: Why did EES and ENS fail to result in fewer articulation errors than ANS in Conditions A and B? The second question is: Why did EES result in significantly fewer errors than ENS when training was provided, but not when training was excluded?

Possibly, an analysis of volition will help provide an answer to the first question. According to Rosenbek et al. (1974) volitional production of phonemes is most affected by DAS. Blakeley (1972) hypothesized the articulators do not profit from experience, thereby reducing volitional control of speech. This investigator suggests the introduction of 
new stress patterns without the time to practice producing them increased the volitional effort necessary to repeat the sentences.

Support for the above suggestion comes from Tonkovich and Marquardt (1977). In Chapter II of the present study it was noted these authors performed an experiment by having adults with apraxia of speech repeat sentence stimuli presented using both melodic intonation and normal stress. They found that melodic intonation did not facilitate articulation. In their discussion of results it was suggested why the use of melodic intonation was not supported. They write:

Since each of the stimulus sentences was presented only once and required an immediate repetition, it appears more volitional effort on the part of the subject was required to produce the response.

It is possible the above statement may apply to the present study as we11. Generally, stimuli were presented only one time and an immediate response was required. Stimuli were presented twice only when a subject had not received or decoded the sentence meaning. This situation may have been partly responsible for the failure of EES and ENS to lead to fewer articulation errors than ANS.

Another possible explanation for this failure is that conditions in which the stress modes are used during management were not exactly duplicated in this study. Discussing adults, Rosenbek (1976) said patients must have "reasonable" control over the phoneme being corrected. In addition, the 
phonetic environment around the target phoneme is carefully controlled so no other sounds which are difficult for the client are present. In the current study all subjects were administered the same stimuli whether or not they had "reasonable" control over the phonemes. Furthermore, the phonetic environment was not adjusted to account for each subject's sound-producing skil1s. It was decided all subjects should respond to the same stimuli in order to reduce the number of variables which might affect the outcome.

Possible facilitative effects of EES and ENS may have been overlooked because of the method of scoring employed in this study. For purposes of this investigation, articulation errors involving one of the consonants in a word resulted in the whole word being scored as incorrect. Therefore, if a child missed both consonants in a word one time, but missed only one consonant another time, both were scored as one error. Another limitation was scoring without regard to severity of the error. For instance, an $/ \mathrm{r} /$ may have been replaced by a $/ w /$ one time and distorted another. Speech clinicians generally agree the first type of error is more severe than the latter. If the scoring had been performed according to severity of error, results may have shown stress to have an effect on articulation.

The second question posed for discussion was: Why did EES result in significantly fewer errors than ENS when training was provided, but not when training was excluded? This 
question will be considered in two parts. First, the one difference in procedure between Condition A and Condition B, training, will be analyzed to see how it may have influenced results. Second, EES and ENS will be analyzed to see what characteristics may have affected results.

Training will be considered first. By training children to hear the different stress patterns, the experimenter sensitized them to differences in the stimuli. Although a criteria check confirmed subjects could discriminate among the modes, subjects were not allotted time to practice them. By increasing awareness of what needed to be imitated, training may have negatively influenced ENS, but not EES.

Next to be considered is what characteristics of the two stress modes caused them to be influenced differently by training. Possibly, ENS required more effort to produce because it required more adjustments of the speech act. If stress is viewed in terms of pitch, loudness, articulation time, and pause time (Rosenbek, 1976), it can be shown more adjustments were made producing ENS than producing EES.

In ENS, primary stress was placed on one word in the sentence. Pitch, intensity, and articulation time were modified for the stressed word during production of the sentence. In addition, pause time preceding the word was increased.

In EES, on the other hand, each parameter remained fairly constant throughout a particular sentence. In addi- 
tion, overall rate of the sentence was reduced, since each word was characterized by increased articulation time and was preceded by a pause.

In conclusion, it has been suggested that training may have affected EES and ENS differently. Possibly, EES was made slightly easier than ANS, and ENS was made slightly more difficult. As a result, the difference between EES and ENS was significant. 
CHAPTER V

SUMMARY AND IMPLICATIONS

\section{Summary}

The use of facilitators to improve the articulation of children having DAS has been encouraged by Rosenbek et al. (1974) and Yoss and Darley (1974). Among the facilitators mentioned are rhythmic body movement, modifications of intonation and stress, and visual cues, such as the written word. Rosenbek et a1. (1974) strongly endorsed the use of stress, especia11y EES.

In a discussion concerning adults, Rosenbek et a1. (1973) described three stress modes they found to be effective. These modes were EES, ENS, and ANS. For articulation training, Rosenbek and his colleagues recommended a shaping procedure beginning with the most facilitative, EES, progressing to ENS, and ending with the least facilitative, ANS. Since it has been suggested that stress is an appropriate tool to use with children, it seems reasonable to extend the use of these three modes to children with DAS.

The purpose of this investigation was to study the effects of three modes of stress on error productions of children with developmental apraxia of speech during a 
sentence repetition task. The study was designed to answer the question:

Will there be a significant difference in the number of errors for each mode when: a) training to distinguish among the stress modes is not provided?

b) training to distinguish among the stress modes is provided?

Secondarily, it was hypothesized EES would have the fewest errors, ENS would have significantly more errors than EES, and ANS would have the most errors when training is not provided and/or when training is provided.

A total of nine subjects with DAS were chosen from the Portland Public Schools and the Portland State University Speech and Hearing Clinic. The children had normal hearing in at least one ear, no concomitant disorder which might affect speech, and a mental age no more than three years below chronological age. The children were seen twice, with a period of at least one week between sessions. Each time they repeated 54 sentences composed of an Article-SubjectVerb-Article-Object presented in random order. Eighteen sentences were recorded using EES, eighteen using ENS, and eighteen using ANS.

The first presentation of stimuli, called Condition A, was preceded by the instruction to repeat the sentences exactly as heard. The second presentation of stimuli, called Condition $B$, was preceded by a training session in. which the child demonstrated the ability to distinguish among the three stress modes. Responses under these two 
Conditions were analyzed for articulatory errors made on the subjects, verbs, and objects. Three comparisons were made with the results from each stimulus situation. The comparisons were: 1) between EES and ENS; 2) between EES and ANS; and 3) between ENS and ANS.

Results revealed a statistically significant difference for one of the six comparisons. EES had significantly fewer errors than ENS in Condition B. Neither EES nor ENS had significantly fewer errors than ANS. These findings do not support the assertion of Rosenbek and his colleagues that EES, followed by ENS, should precede the use of ANS in training.

\section{Implications}

\section{$\underline{\text { Research }}$}

More research should be conducted on the use of stress patterns to facilitate correct articulation with children having DAS. Perhaps prospective researchers should conduct single-subject studies. By doing so, they would be able to avoid some of the problems created by lack of a sufficient number of subjects having DAS without other speech and language disorders.

In single-subject studies, experimental conditions might be individualized so the subject's level of articulation ability could be taken into account. For example, a subject using /s/ at the phrase level might be asked to 
repeat phrases containing this sound. It is possible the facilitative effects of stress patterns depend on the level of sound-making.

Future researchers may benefit by scoring articulation according to the degree of error. This procedure may expose a tendency of stress patterns to facilitate correct articulation which was concealed by the scoring method used in this study. Perhaps not all children with DAS have the potential to articulate sounds perfectly, yet their productions may improve significantly when modification of stress patterns is part of treatment. Scoring procedures should be sensitive enough to reveal improvement.

Fina1ly, investigators might compare the effect of audio-visual stimuli with auditory stimuli. According to Rosenbek et al. (1974), the use of the visual modality improves response adequacy.

\section{Clinica1}

Although modification of stress did not appear to facilitate articulation in either Condition, there was some indication it may be useful following sufficient training. The difference between EES and ANS, although not significant, did increase in the training situation, and EES had significantly fewer errors than ENS. It seems possible modification of stress is a more potent method following extensive training of the type used in this study. 
In conclusion, it is recommended that clinicians continue experimenting with the use of stress in the treatment of DAS. By following a carefully controlled treatment plan which includes teaching clients to hear differences in stress, it would appear training may be made more effective. 
B I B L I O G R A P H Y 


\section{B IBLIOGRAPHY}

ATENS, J., JOHNS, D., and DARLEY, F., Auditory perception of sequenced words in apraxia of speech. J. Speech Hearing Res., 14, 131-43 (1971).

BLAKELEY, R., The Practice of Speech Pathology: A Clinical Diary. Springfie1d, I11.: Charles C. Thomas (1972).

BLOOM, L. and LAHEY, M., Language Development and Language Disorders. New York: John Wiley and Sons (1978).

BROWN, S.F., The loci of stutterings in the speech sequence. J. Speech Hearing Dis., 10, 181-92 (1945).

CHAPPELL, G.E., Childhood verbal apraxia and its treatment. J. Speech Hearing Dis., 38, 362-68 (1973).

DEAL, J.L. and DARLEY, F.L., The influence of linguistic and situational variables on phonemic accuracy in apraxia of speech. J. Speech Hearing Res., 15, 639-53 (1972).

DISIMONI, F.G. and DARLEY, F.L., Effect on phoneme duration control of three utterance length conditions in an apractic patient. J. Speech Hearing Dis., 42, 257-64 (1977).

DUNLOP, J.M. and MARQUARDT, T.P., Word production in apraxia of speech. Cortex, 13, 17-29 (1977).

EDWARDS, M., Developmental verbal dyspraxia. Brit. J. Dis. Comm., 64-70 (1973).

FAWCUS, R., The psychological and physiological basis of articulatory performance. Brit. J. Dis. Comm., 6, 99106 (1971).

FERRY, P.C., HALL, S.M., and HICKS, J.L., Verbal dyspraxia in children: a neurological cause of "poor speech." J. Oregon Speech Hearing Assoc., 13, 14-19 (Fa11, 1974).

HARDISON, D., MARQUARDT, T., and PETERSON, H., Effects of selected linguistic variables on apraxia of speech. J. Speech Hearing Res., 20, 334-43 (1977). 
LENNENBERG, E.H., Biologica1 Foundations of Language. New York: John Wiley and Sons (1967).

MARTIN, A.D., Some objections to the term apraxia of speech. J. Speech Hearing Dis., 39, 53-64 (1974).

MORLEY, M. and FOX, J., Disorders of articulation: theory and therapy. Brit. J. Dis. Comm., 4, 151-65 (1969).

ROSENBEK, J., Treatment of apraxia: prevention, facilitation, and reorganization. A paper presented at the American Speech and Hearing Association convention, Hous ton (1976).

ROSENBEK, J., Veterans Administration, Madison, Wisconsin. Telephone Interview (March, 1978).

ROSENBEK, J. and WERTZ, R., A review of fifty cases of developmental apraxia of speech. Lang. Speech Hearing Serv. Schoo1s, 3, 23-33 (1972).

ROSENBEK, J., LEMME, M. , AHERN, M. , HARRIS, E. , and WERTZ, R., Advances in the treatment of apraxia of speech. A paper presented to the third conference on Clinical Aphasiology, Albuquerque, New Mexico (1973).

ROSENBEK, J., WERTZ, R., and DARLEY, F.L., Oral sensation and perception in apraxia of speech and aphasia. J. Speech Hearing Res., 16, 22-36 (1973).

ROSENBEK, J., HANSEN, R., BAUGHMAN, C. , and LEMME, M., Treatment of developmental apraxia of speech: a case study. Lang. Speech Hearing Serv. Schools, 5, $13-22$ (1974).

SPARKS, R.W. and HOLLAND, A.L., Method: Melodic Intonation Therapy for aphasia. J.Speech Hearing Dis., 41, 287-97 (1976).

TONKOVICH, J.D. and MARQUARDT, T.P., The effects of stress and melodic intonation on apraxia of speech. In Brookshire, R.H., Clinical Aphasiology Conference Proceedings, Minneapolis Book Pub. (1977).

YOSS, K.A. and DARLEY, F.L., Therapy in developmental apraxia of speech. Lang. Speech Hearing Serv. Schools, 5, 2331 (1974). 


$$
\text { A P P E N D I C E S }
$$




\section{APPENDIX A \\ SPECIFICATIONS OF ELECTRONIC EQUIPMENT USED IN THE STUDY}

1. Ar-Tik Speech and Hearing Recorder. This magnetic tape deck was manufactured for Arion Products by Tanberg of America, Inc. Frequency response is $50-12,000 \mathrm{~Hz}$ for record and playback. Flutter and wow were determined to be . 2 percent. (These specifications were not provided by the manufacturer; hence, the above was determined by the electronics technician in the language laboratory at Portland State University).

2. Language Master, Mode1 717. This instrument was manufactured by Bell and Howell. It operates on 110-120 volts, 60 cycles A. C., and draws about 80 watts. The amplifier delivers $2-2 \frac{1}{2}$ watts of power at the jack, across which there is a $3 \mathrm{ohm}$ impedance.

3. Beltone Portable Audiometer, Mode1 10-D. This audiometer was manufactured by Beltone Electronic Corporation. The manufacturer reports the following specifications:

Power Source: 110 or 220 volts A. C. only; 50-60 cycles

Current: $0.0555 \mathrm{amp}$ at $110 \mathrm{~V}$ or 0.027 amp at $220 \mathrm{~V}$

Power Consumption: 6 watts

Frequency Range (Air): 125 to 8000 CPS

Accuracy of Frequency Calibration: Less than $2 \%$ variance of indicated frequency at all frequencies

Accuracy of SPL (Air Calibration): Within $3 \mathrm{~dB}$ of indicated leve1

Distortion: All harmonics of any frequency are no greater than $25 \mathrm{~dB}$ below the fundamental frequency

Tone Interruption: Approximately 0.1 second for complete rise and decay of tone 
Continuous1y Variable Decibel Intensity Control: Dial graduated in $1 \mathrm{~dB}$ increments

Range of Attenuation: Available in ASA 1951 Values or ISO 1964 Values. ASA dial indications are -10 to $100 \mathrm{~dB}$. ISO dial indications are 0-110 dB.

Attenuator Linearity: Within $1.5 \mathrm{~dB}$ for every $5 \mathrm{~dB}$ interval within the range of attenuation, with an accumulated tolerance of less than $4 \mathrm{~dB}$ over the entire range

Signal-to-Noise Ratio (pure tone): $-60 \mathrm{~dB}$ or better 
A.

1. The rat bit the cheese.

2. The rat bit the cheese.

3. The rat bit the cheese.

4. The rat bit the cheese.

5. The rat bit the cheese.

6. The rat bit the cheese.

7. The rat bit the cheese.

8. The rat bit the cheese.

9. The rat bit the cheese.

EES

"

$"$

ENS

"

ANS

"

11

B.

1. The pig caught the fish.

2. The pig caught the fish.

EES

"

"

4. The pig caught the fish.

ENS

5. The pig caught the fish.

6. The pig caught the fish.

7. The pig caught the fish.

8. The pig caught the fish.

9. The pig caught the fish.

"I

11

ANS

"I

it

C.

1. The man sewed the sock.

2. The man sewed the sock.

EES

3. The man sewed the sock.

4. The man sewed the sock.

5. The man sewed the sock.

6. The man sewed the sock.

7. The man sewed the sock.

8. The man sewed the sock.

9. The man sewed the sock.

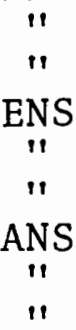

D.

1. The duck took the juice.

2. The duck took the juice.

EES

3. The duck took the juice.

4. The duck took the juice.

5. The duck took the julice.

6. The duck took the juice.

7. The duck took the juice.

8. The duck took the juice.

9. The duck took the juice. 
E.

1. The sheep chewed the $10 \mathrm{~g}$.

2. The sheep chewed the $10 \mathrm{~g}$.

3. The sheep chewed the log.

4. The sheep chewed the $10 \mathrm{~g}$.

5. The sheep chewed the log.

6. The sheep chewed the log.

7. The sheep chewed the 10g.

8. The sheep chewed the log.

9. The sheep chewed the log.

EES

$"$

it

ENS

11

i1

ANS

"

it

F.

1. The bear shook the pole.

2. The bear shook the pole.

3. The bear shook the pole.

4. The bear shook the pole.

5. The bear shook the pole.

6 . The bear shook the pole.

7. The bear shook the pole.

8. The bear shook the pole.

9. The bear shook the pole.

EES

i1

11

ENS

"

ANS

"

" 


\section{APPENDIX C}

\section{TRAINING PROCEDURE FOR CONDITION B}

The procedure for training subjects to distinguish the differences among the three stress modes utilized one or more of the following sentences: The knife cut the meat, the cat fought the dog, and the thief hid the ring.

The training procedure always began with the experimenter stimulating the subject by presenting sentences using the stress modes. Stimulation began with EES, followed by ENS, and ending with ANS. The investigator presented each mode using live voice and tape recordings. He explained that certain words were given either big or little punches (stress). To provide a visual image for each stress mode, he showed cards with pictures of punching gloves. EES was represented by five large gloves; ENS by one large glove; and ANS by one small glove. Following is an example of the procedure using EES.

\section{EXPERIMENTER:}

We can say a sentence different ways. For instance, we can give each word a big punch with our voices. (Experimenter says sentence using EES. He then shows the stimulus card representing EES). This card has five boxing gloves. This means when someone says a sentence like the one I just said, he gives all five words a big punch with his voice. Listen to this (tape). (Experimenter presents tape of sentence while pointing to card).

This procedure was used for each of the stress modes.

Following the stimulation procedure, the experimenter placed the three stimulus cards on the table and shuffled the nine productions of the practice sentence used. He then presented the recordings on the Language Master and the subject pointed to the appropriate card. Criteria for passing was $2 / 3$ correct in each mode.

If the subject missed $2 / 3$ in any mode, the experimenter reviewed the sentences and asked the subject to identify the stress modes. Errors were corrected and correct responses were reinforced using social praise. A 
second set of nine cards was then presented and the subject identified productions. Only productions in the stress mode failed were scored. Criteria remained $2 / 3$ correct. This procedure continued until all three modes were passed. 


\section{APPENDIX D}

SEX, CHRONOLOGICAL AGES; MENTAL AGES, AND SCORES OF SUBJECTS

$\begin{array}{cccccccccc}\text { Subject } & \text { Sex } & \text { C.A. } & \text { M.A. } & \text { A } & \text { B } & \text { A } & \text { B } & \text { A } & \text { B B } \\ 1 & \text { M } & 8 & 9-8 & 10 & 6 & 10 & 8 & 9 & 7 \\ 2 & \text { M } & 8 & 8-3 & 17 & 17 & 17 & 18 & 17 & 16 \\ 3 & \text { M } & 8 & 10-0 & 26 & 24 & 24 & 26 & 27 & 25 \\ 4 & \text { M } & 9 & 10-2 & 6 & 4 & 5 & 3 & 5 & 10 \\ 5 & \text { M } & 10 & 7-6 & 34 & 36 & 33 & 40 & 37 & 38 \\ 6 & \text { M } & 7 & 5-1 & 54 & 54 & 54 & 54 & 54 & 54 \\ 7 & \text { M } & 8 & 6-10 & 6 & 9 & 7 & 10 & 7 & 9 \\ 8 & \text { F } & 10 & 8-1 & 22 & 15 & 20 & 17 & 18 & 16 \\ 9 & \text { F } & 8 & 5-5 & 22 & 19 & 23 & 23 & 25 & 19\end{array}$

